\title{
DESIGN OF INTELLIGENT TRANSPORT RELATED ISSUE SYSTEM BASED ON ARM7
}

\author{
C.V.L.Sameera ${ }^{1}$, M. Veda Chary ${ }^{2}$ \\ ${ }^{1}$ M. Tech, ${ }^{2}$ Assoc Prof, Dept of ECE, CMR College of Engineering \& Technology, Hyderabad, AP. \\ lakshmisameera.1@gmail.com
}

\begin{abstract}
Now-a-days mode of transportation playing a major role in transport related problems. Every day millions of vehicles are passing through roads, mainly in this transport related issues Time, safety and efficiency are the major factors why because mode of transportation plays an important role in urbanization. Through this paper integrated solution has been offered to the transport related issues based on ARM7. Hence ARM7 is the core which has hardware modules such as RFID,GSM and SPEED SENSOR(split counter) to handle the new transport related problems viz., special zone(school zones, hospital zones, army zones), toll gate control, parking slot management and traffic rule violation control are explained in this paper. A professional exploitation of communication link between RF Modems over a wireless channel to facilitate vehicle monitoring, vehicle verification and automated toll collection on highways is proposed
\end{abstract}

Keywords: GSM, IR SENSOR, RFIDTAG, RFID READER, SPEED SENSOR (SPLIT COUNTER) $* * *$

\section{INTRODUCTION}

In this modern world we are facing a number of transport related problems. By using RFID technology can effectively used to solve some of the problems like traffic rule violation control, parking slot arrangement, tollgate management, special zones and traffic signal management. One RFID module(RFID tag) is placed in the vehicle with owner info, $\mathrm{RC}$ book, insurance details, service details etc. to send vehicle identification to traffic information database the other RFID MODULE(RFID reader) will be placed with embedded controller. Toll Gates, Parking areas and also in traffic signal areas the process is same. Data will be sending to mobile number from which number we will receive the message.

We placed GSM module with embedded unit in the moving vehicle to transmit vehicle information to different points. The system reads area information and then the details are transmitted to the specific numbers stored in database (Police station, Owner and Hospital). Special zone information, it alerts driver about the zone if the driver exceeds the speed limit automatically the buzzer gets 'on' if he reduce the speed the buzzer got off if not with the help of split counter the speed reduced automatically. This information with how much speed the driver was going in the special zones is send through GSM to the resp., (Police station, Owner). Whenever the vehicle entering in to the parking area, the reader identifies the vehicle and allots particular slot and also initiates bill creation at the time of exit. Almost similar concept is followed in Automated Toll gate system. Whenever the vehicle crosses the traffic signal area, the data from Vehicle tag is read and based on the traffic density, traffic signal is enabled. By this traffic problem is managed intelligently. If vehicle insurance is not renewed in time, the traffic police will be alerted. Figures show on board vehicle system, traffic light controls, toll gate management, parking slot arrangement.

\section{TECHNICAL OVERVIEW}

\subsection{RFID}

RFID is an auto ID device like Barcode, Smart cards. Special feature of this technology is that there is no need of line of sight reception as required in some other technologies. In RFID systems the items are marked with tags a person, product or animal. In this work we are using Active RFID tags because of its low power consumption and have greater range up to $100 \mathrm{~m}$. In RFID systems the items are marked with tags .These tags contain transponders that emit messages readable by specialized RFID readers. Most RFID tags store some sort of identification number; for example a customer number or product code. A reader retrieves information about the ID number from a database, and acts upon it accordingly.

RFID tags are of two general categories, active and passive, depending on their source of electrical power. Active RFID tags contain their own power source, usually an on-board battery. Passive tags obtain power from the signal of an external reader. RFID readers also come in active and passive varieties, depending on the type of tag they read. Then based on their frequency range of transmission it is classified as LF, $\mathrm{HF}$, VHF and UHF tags. 
- $\quad$ RFID operating frequency range is $125-134 \mathrm{KHz}$.

- RFID tags can also contain writable memory, which can store information for transfer to various RFID readers in different locations.

- RFID cards and readers are becoming low cost.

These aspects are the primary reasons for rapidly growing RFID based authentication system.

\subsection{GSM:}

Every day, millions of people are making phone calls by pressing a few buttons. Minute is known about how one person's voice reaches the other person's phone that is thousands of miles away. Even less is known about the security measures and protection behind the system. GSM(Global System for Mobile Communications). GSM is a common European mobile telephone standard for a mobile cellular radio system operating at $900 \mathrm{MHz}$ It has been a great success in providing both voice and low speed Throughout the evolution of cellular telecommunications; various systems have been developed without the standardized specifications resulting in many problems directly related to compatibility. The GSM standard is intended to address these problems. In the current work, SIM300 GSM module is used The mobile communications has become one of the driving forces of the digital revolution.

\subsection{ARM7:}

The ARM7 is the highest performance and most power efficient processor currently in production today ARM7TDMI based LPC 2148 micro controller is a 32-bit microcontroller Which contains an on chip static RAM of $8 \mathrm{kB}$ to $40 \mathrm{kB}$ and on-chip flash memory of $32 \mathrm{kB}$ to $512 \mathrm{kB}$, and abundant internal and external resources. It is a 32-bit RISC architecture with 16 registers and a harvard memory architecture. It can run at speeds between $600 \mathrm{MHz}$ to over $1 \mathrm{GHz}$ while averaging as little as $300 \mathrm{~mW}$ of power. The ARMv7 architecture includes two pipelines: a 13-stage integer pipeline and a 10-stage NEON pipeline (useful for accelerating multimedia and signal processing applications.

\subsection{SPLIT COUNTER (MOC7811):}

General MOC7811 is a slotted Opto isolator module, with an IR transmitter \& a photodiode mounted on it. Performs NonContact Object Sensing. This is normally used as positional sensor switch (limit switch) or as Position Encoder sensors used to find position of the wheel. It consists of IR LED and Photodiode mounted facing each other enclosed in plastic body.
- Slot width: $3 \mathrm{~mm}$.

- Slot depth: $7 \mathrm{~mm}$

Applications:

- DC motor position / velocity control.

- Position and velocity servomechanisms.

- Factory automation robots.

- Numerically controlled machinery.

- Computer printers and plotters

\subsection{TIMER AND TSOP1738:}

555 timer IR sensor. IR Transmitter and Receiver pair can be easily made using 555 Timer, IR LED andTSOP1738 IR Receiver. This can be used for remote controls, burglar alarms etc. TSOP1738 is a very commonly used IR receiver for PCM remote control systems. It has only 3 pins, Vcc, GND and Output. It can be powered using a $5 \mathrm{~V}$ power supply and its active low output can be directly connected to a microcontroller or microprocessor. It has high immunity against ambient light and other electrical disturbances. It is able to transfer data up to 2400 bits per second. The PCM carrier frequency of TSOP1738 is $38 \mathrm{KHz}$, so we want to design a stable multivibrator of $38 \mathrm{KHz}$. This can be done by using 555 Timer.

\section{HARDWARE BASED SYSTEM DISCRIPTION}

In the current work we have designed. Following hardware systems are

1. ARM7 board vehicle system.

2. Special zone alerting facility.

3. Parking slot arrangement system.

4. Toll gate management system.

5. Traffic control system.

6. Alert receiver unit.

\subsection{ARM7 Board Vehicle System:}

This is at vehicle side system consist of ,GSM module(SIM 300 GSM module) to transmit alert data to the mobile receivers already configured, vehicle information RFID Tag and ARM7 embedded module, split counter (speed sensor). GSM is connected to receive and transmit of the serial port in embedded module. The total controller program is developed in embedded $\mathrm{C}$ language and is downloaded into the memory for operation. Here we use semi passive tag to transmit vehicle database like insurance details (renewal date and expiry date), $\mathrm{RC}$ book and license etc., to traffic organizers. This data is collected in the RFID reader enabled traffic signal areas in a very intelligent way.

- Size: Refer to the image below.

- Mounting hole diameter: $3 \mathrm{~mm}$.

- Mounting hole spacing: $19 \mathrm{~mm}$. 


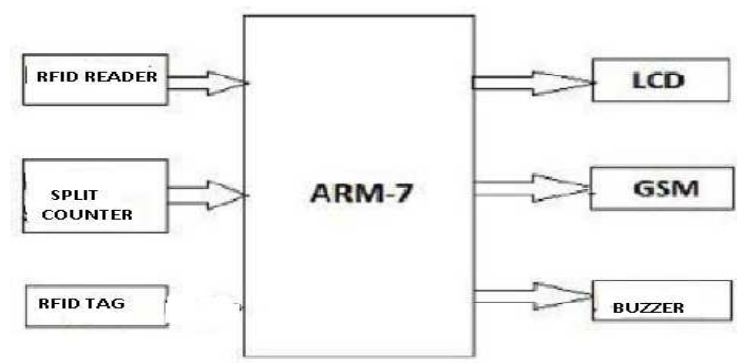

Fig.1 On Board Vehicle System.

\subsection{Special Zone Alerting Facility:}

In this unit we have used alert on special zones like school, hospital, weak bridges and zigzag bends etc through RFID module. At the time ARM7 produces message which will be displayed on LCD and automatically buzzer beeps. The alert information can be dynamically changed like damage in bridge, condition of road and new changes in road (one way or two ways and other diversion indications) etc. it alerts driver about the zone if the driver exceeds the speed limit automatically the buzzer gets 'on' if he reduce the speed the buzzer got off if not with the help of split counter the speed reduced automatically. This information with how much speed the driver was going in the special zones is send through GSM to the resp., (Police station, Owner).

\subsection{Parking Slot Arrangement System:}

This unit consists of AtmelS52 microcontroller, RFID reader, Stepper motor and IR sensors. RFID reader, Stepper motor and IR sensors are connected with serial port of the system to sense the vehicle and for allotting the parking area. Billing is done through this module by counting the time. The entry and exit gate is automated by stepper motor.IR sensor is used to sense whether the vehicle is parked at the correct place. In our country the present method of parking slot allotment and billing is manual. It requires manpower and some times billing issues may arise. Our proposed system is low cost and fast processing method. Developed countries like USA, UK, Europe etc, are using RFID based systems, but we propose low cost implementation.

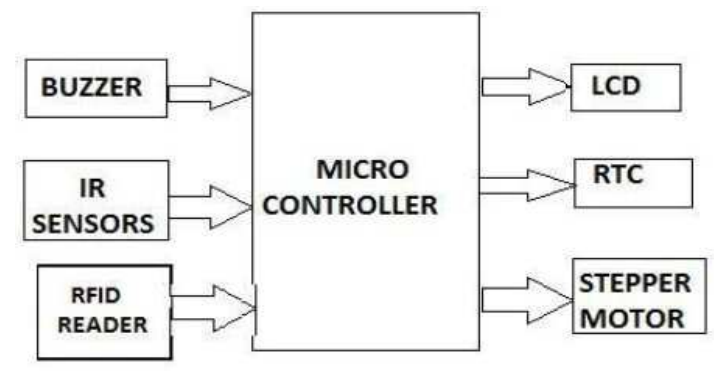

Fig.2 Parking slot Management System

\subsection{Toll Gate Management System:}

This unit is similar to the previous one. Here in this we are using microcontroller, RFID reader and stepper motor. The vehicle number is identified by the reader and bill is generated faster. By this we can automate toll gates with latest RFID system. Time saved more in highways.

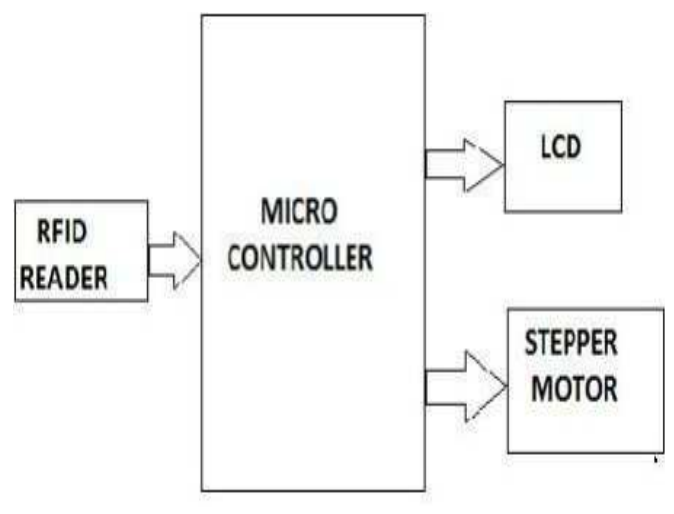

Fig.3 Toll Gate System

\subsection{Traffic Control System:}

In this module we are using Atmel S52 microcontroller as a base unit and RFID reader is connected with serial port of the system. The conventional traffic signal controller works on the principle of Time division. It is rigid method and does not consider traffic density in a particular direction. Here we are proposing a low cost modified adaptive architecture with RFID enabled system. We use external antenna based readers. Instead of using single antenna, array of antennas used here to give better results. The general time division based traffic signal management will create massive traffic problems in peak hours. But our system is adaptive system based on vehicle density calculation. Whenever the vehicle crosses the traffic signal area, the data from Vehicle tag is read and based on the traffic density, traffic signal is enabled. By this traffic problem is managed intelligently. If vehicle insurance is not renewed in time, the traffic police will be alerted. It will give perfect solution for the traffics problem faced by previous one.

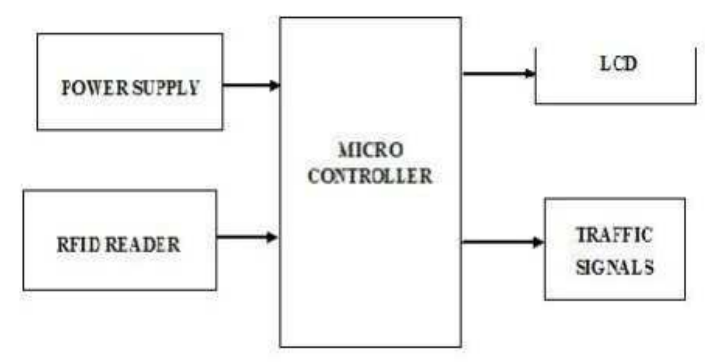

Fig.4 Traffic Control Unit 


\subsection{Alert Receiver Unit:}

This unit is nothing but alert receiving "mobile phone" programmed in the embedded module. It may be owner of the vehicle, the hospital emergency care and the police station information number.

\section{WORKING PRINCIPLE}

In this we have used ARM7 as a core device. GSM module, RFID tag and split counter (speed sensor) are serial port of the controller. Special zones like School, Hospital, Zig Zag bends and weak bridge etc., whenever vehicle crossing that area, embedded module will alert the driver to reduce acceleration. Using split counter

We can calculate the speed; if the driver won't reduce the speed it will automatically reduce the speed and sends a message to the corresponding persons. The system interaction has been explained in fig1.

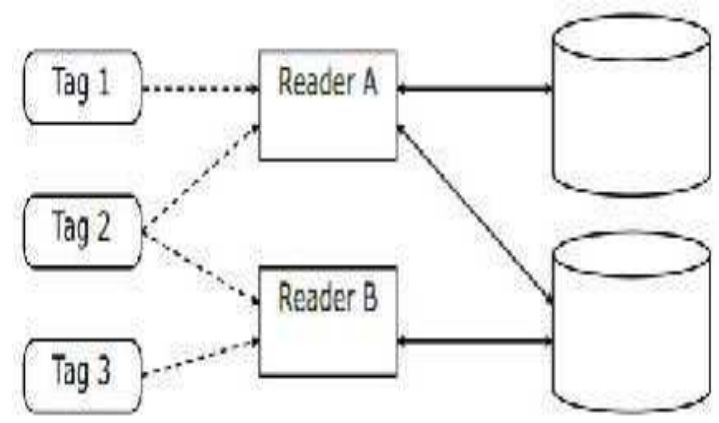

Fig-5 RFID System Interaction

This will as control accident ratio. In addition to embedded module one special RFID Tag is placed inside vehicle to transmit vehicle information. In the traffic signal management system RFID reader and display informer unit are connected with serial port of the microcontroller. If vehicle insurance, pollution test, FC is not proper, the alert system will produce beep sound and vehicle number is displayed. Then the traffic police can easily alert the driver / owner. Traffic signal is managed by counting the number of vehicles crossing the reader area in a particular time interval. Here the data collected by the antennas are given to the reader via multiplexer switch. This method will save RFID reader usage and money. By this we can manage the traffic intelligently. For parking management the reader is placed at the entrance of the parking area and the gate is controlled by stepper motor. The vehicle number is read by the reader then parking slot is announced and stepper motor is activated to open the gate. The bill is automatically generated while the vehicle is entering in to the exit gate. Similarly toll is managed by the RFID system placed in the toll areas.

\subsection{Implementation of Autonomous Vehicle on} ARM-7:

This is semi autonomous vehicle using an ARM7 microcontroller, GSM, RFID module, SPLIT COUNTER (speed sensor) device for the develop of a traffic rule violation control and special zones. For Software developing in the module Keil's -uVision3 development environment along with ARM-GCC compiler used. Keil's uVision3 development environment along with ARM-GCC compiler. For flash programming the LPC2000 Flash Utility V2.2.1 has been used.

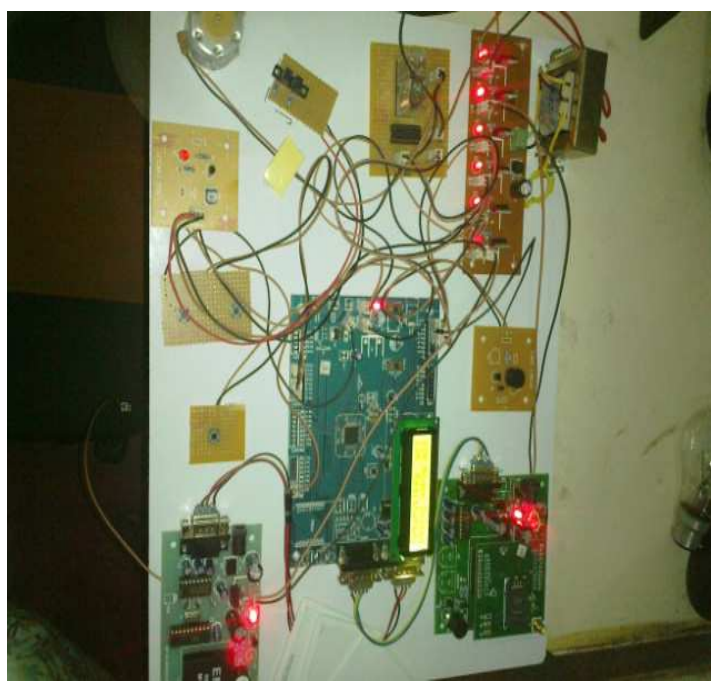

Fig-6 Experimental overview of the project (1)

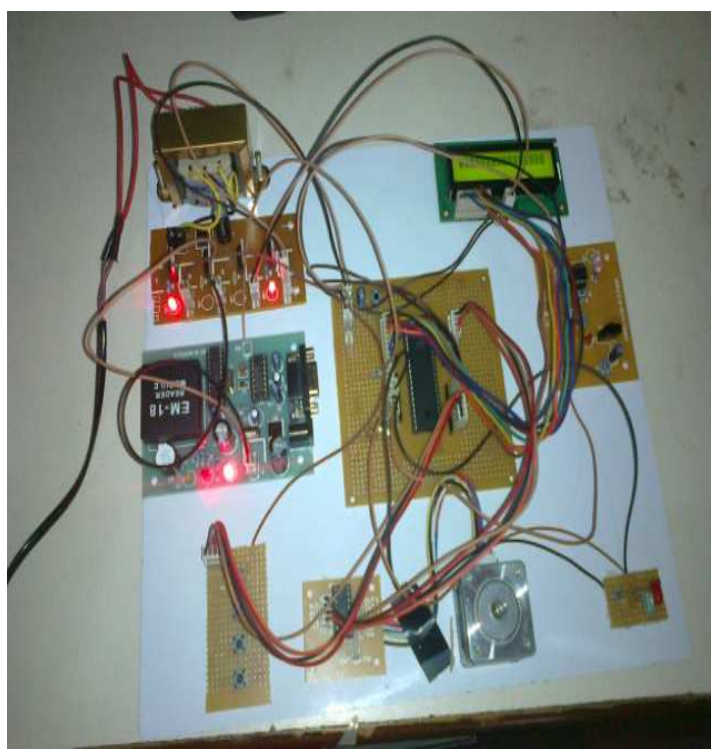

Fig-7 Experimental overview of the project (2) 


\section{CONCLUSIONS}

This paper mainly reviewed the research and Development Work for traffic and transport related problems such as accident alert, Toll gate control, traffic signal control, traffic rules violation control, parking management and special zone alert using the latest GSM, RFID technology. In this project we have designed a system to give complete solution. It is proposed as a low cost optimized solution using RFID and GSM mobile technology. This is in line with the developed countries like USA, England, German and Japan, where RFID, ZIGBEE, GPS and GSM technologies are widely used for traffic management. But in India we have not implemented any automated system for transport management due to prohibitive cost. Keeping this in mind we have proposed this system at low cost.

\section{REFERENCES}

[1] F.Abdessemed (2011). An integrated system for tracking and control pilgrims shuttle buses. Member IEEE, Washington, DC, USA.

[2] Muzahid Hussian, Abhishek tayal, Sarabjot singh(2011). Position Matching Based Autonomous Speed Regulation System for Vehicles. Thapar University, Patiala, India.

[3] Manish Bauhptani, Shahram Moradpour,

"RFID Field Guide-Developing Radio Frequency

Identification Systems", Prentice Hall, 2005, pp 7-9, 16-225, 160,231

[4]Bemstein, D.kornhauser, A. (1996).An interdiction to map matching for personal navigation assistants. Technical report, new jersesy TIDE center, Princeton University, USA

[5] Sewon Oh, Joosang Park, Yongioon Lee, "RFID based Middleware System for Automatic Identification", IEEE International Conference on Service Operations and Logistics, and Information, 2005

[6] Shi-Cho Cha Kuan-Ju Huang Hsiang-Meng Chang, " An Efficient and Flexible Way to Protect Privacy in RFID Environment with Licenses ", IEEE International

Conference RFID, April 16-17, 20

\section{BIOGRAPHIES:}

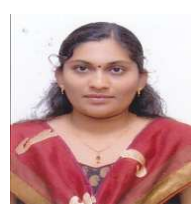

C.V.L. Sameera received her B. Tech degree in Electronics \& Communication Engineering from JNTU, Hyderabad, and currently pursuing $M$. tech in embedded systems from JNTU Hyderabad

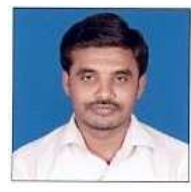

M. Veda Chary received his M. Tech degree in Electronics \& Communication Engineering from JNTU, Hyderabad, currently working as an Associate Professor, ECE in CMR College of Engineering \& Technology, Hyderabad. 